LA-UR- $96-3148$
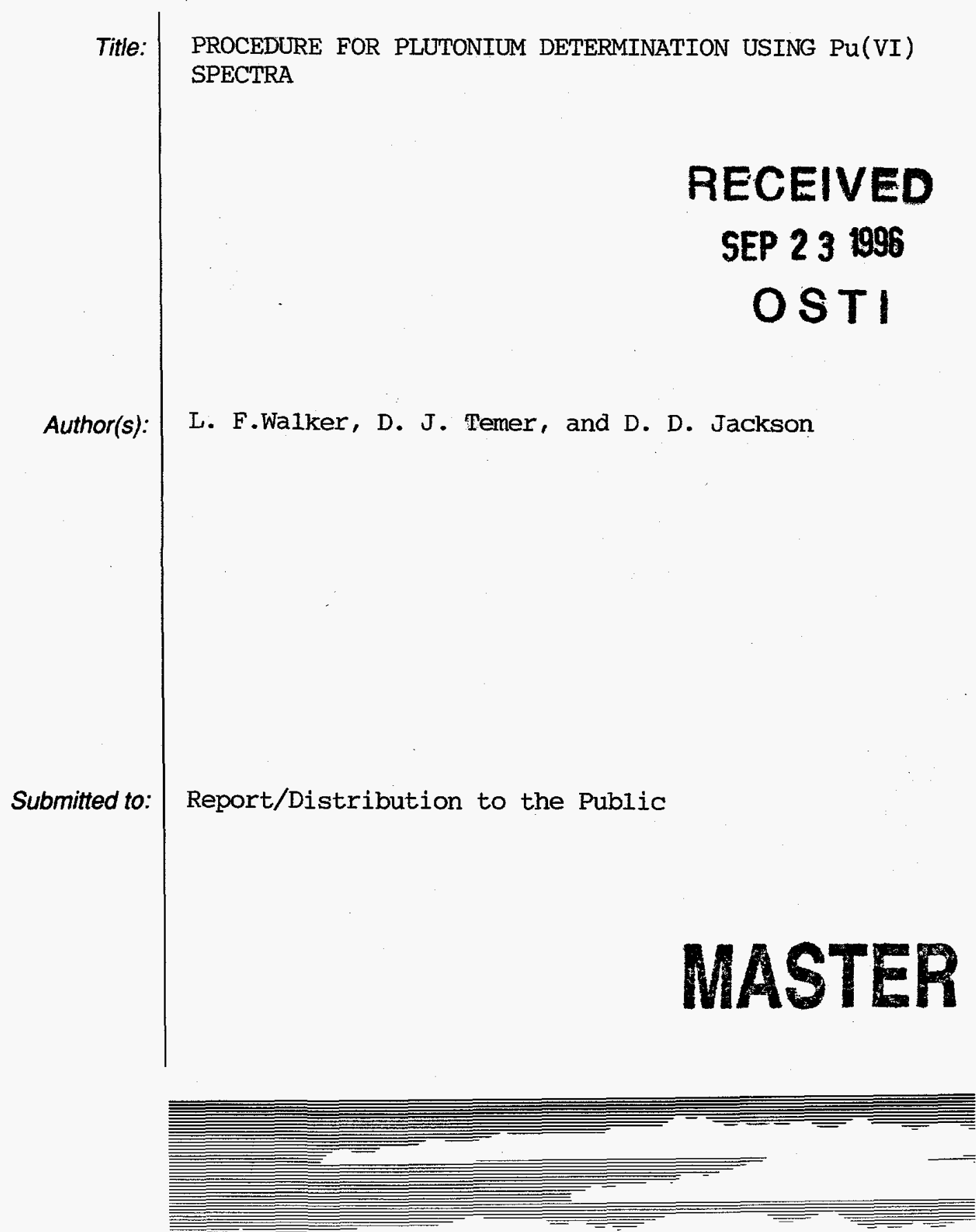

Los Alamos National Laboratory, an affirmative action/equal opportunity emplozer, is operated by the University of California for the U.S. Department of Energy under contract W-7405-ENG-36. By acceptance of this article, the publisher recognizes that the U.S. Government retains a nonexclusive, royalty-free license to publish or reproduce the published form of this contribution, or to allow others to do so, for U.S. Government purposes. The Los Alamos National Laboratory requests that the publisher identify this article as work performed under the auspices of the U.S. Department of Energy. 


\section{DISCLAIMER}

Portions of this document may be illegible in electronic image products. Images are produced from the best available original document. 


\section{DISCLAIMER}

This report was prepared as an account of work sponsored by an agency of the United States Government. Neither the United States Government nor any agency thereof, nor any of their employees, makes any warranty, express or implied, or assumes any legal liability or responsibility for the accuracy, completeness, or usefulness of any information, apparatus, product, or process disclosed, or represents that its use would not infringe privately owned rights. Reference herein to any specific commercial product, process, or service by trade name, trademark, manufacturer, or otherwise does not necessarily constitute or imply its endorsement, recommendation, or favoring by the United States Government or any agency thereof. The views and opinions of authors expressed herein do not necessarily state or reflect those of the United States Government or any agency thereof. 


\title{
Procedure for Plutonium Determination using Pu(VI) Spectra
}

by

\author{
L. F. Walker, Donald J. Temer, and Darryl D. Jackson
}

\begin{abstract}
This document describes a simple spectrophotometric method for determining total plutonium in nitric acid solutions based on the spectrum of $\mathrm{Pu}(\mathrm{VI})$. Plutonium samples in nitric acid are oxidized to $\mathrm{Pu}(\mathrm{VI})$ with $\mathrm{Ce}(\mathrm{IV})$ and the net absorbance at the $830 \mathrm{~nm}$ peak is measured.
\end{abstract}

\section{Introduction}

Plutonium exhibits distinctive spectra in several oxidation states. In the +6 state, it has a very sharp peak at $831 \mathrm{~nm}$ and a maximum molar absorptivity of 500 (1). Because of these two features, it has been used by several laboratories to quantitate plutonium (2-5). Ozone, argentic oxide, perchloric acid, and cerium(IV) have been used to quantitatively oxidize plutoniun to the +6 oxidation state. We have chosen cerium(IV) because if its rapid response, ease of handling, and stability in the system. With cerium oxidation, our quantitation of total plutonium as $\mathrm{Pu}(\mathrm{VI})$ in a $2 \mathrm{M} \mathrm{HNO}_{3}$ system is similar to that used by Savage and Cook (5). An example spectrum is shown below.

\section{Pu(VI) Spectrum}

$0.1 \mathrm{mg} \mathrm{Pu} / \mathrm{ml}$

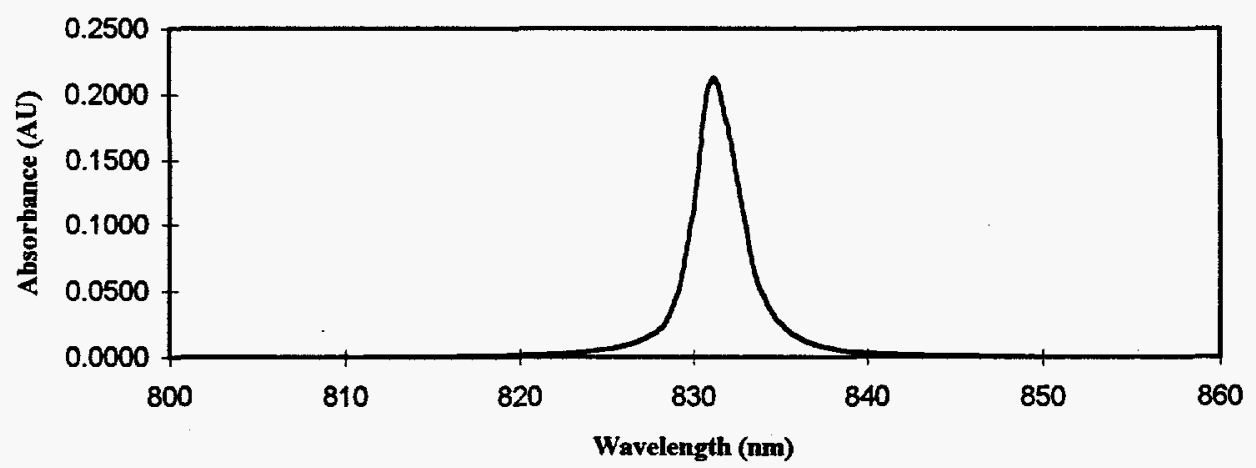

This method applies to plutonium nitrate solutions with plutonium concentrations $>1 \mathrm{~g} / \mathrm{l}$. It is ideal for production lines utilizing nitric acid dissolution of plutonium containing materials and for nitrate waste streams. The precision is $0.2 \%$ for high purity streams with plutonium concentrations $>50 \mathrm{~g} / \mathrm{l}$ and is typically better than $1.0 \%$ even for streams with plutonium concentration as low as $1 \mathrm{~g} / \mathrm{l}$ containing large quantities of impurities. The method is tolerant of many impurities including $\mathrm{Al}, \mathrm{Fe}, \mathrm{Na}, \mathrm{Mg}, \mathrm{Ni}, \mathrm{Cr}, \mathrm{Zn}, \mathrm{Mo}, \mathrm{F}$, and $\mathrm{PO}_{4}$ at levels exceeding the plutonium content itself (6). The keys to success using this method are in the precision of the sampling and instrumentation. 


\section{Sampling}

This method is designed for use with plutonium samples in nitric acid. Determine the volume of sample to take using the table in the Appendix and the estimated plutonium concentration. The sample volume should not exceed $1 \mathrm{ml}$ and should contain 1 to $10 \mathrm{mg}$ of plutonium. We recommend using calibrated microliter pipettes. The precision of the assay can be no better than that of the sampling. Use of a single pipette for dispensing both samples and standards will avoid the bias between pipettes and is encouraged.

Because the absorbance is very sensitive to the nitric acid concentration, the acidity of the sample must be determined and adjusted if it is significantly different than the nominal $2.0 \mathrm{M}$ of the assay system. Changing the overall nitric acid concentration by as little as $0.02 \mathrm{M}$ can affect the measured absorbance by $0.1 \%$. The contribution to the assay for not adjusting the nitric acid concentration in the extreme case of a sampling volume of 1 $\mathrm{ml}$ at an acidity of $16 \mathrm{M}$ can be as large as $1 \%$. Adjustments are made by adding water to the assay flask to compensate for the acidity and size of the sample aliquant. The table in the Appendix gives suggested adjustments for various sample concentrations and acidities.

\section{Standards}

A plutonium solution in $2 \mathrm{M} \mathrm{HNO}_{3}$ at approximately $5 \mathrm{mg} \mathrm{Pu} / \mathrm{ml}$ is made by dissolving three grams of high purity plutonium oxide with the nitric acid sealed reflux system (7). The solution is transferred to a beaker and fumed to near dryness, redissolved in $2 \mathrm{M}$ $\mathrm{HNO}_{3}$ and fumed to near dry again. The plutonium nitrate is finally transferred to a clean $500 \mathrm{ml}$ volumetric and made to volume with $2 \mathrm{M} \mathrm{HNO}_{3}$. The resulting solution is assayed for plutonium using coulometric assay to verify the concentration of the solution. Since changes in temperature will affect the volume, and therefore the sampling when volumetric sampling is used, the density is measured and the temperature noted for reference so corrections can be applied if needed. The plutonium stock solution prepared in this manner is stable for $>1 \mathrm{yr}$. If the stock solution has not been used for an extended period, as a precaution, we recommend verification of the plutonium concentration before use. Three grams of plutonium oxide is enough for about 70 calibration curves. Since volumetric sampling is sensitive to temperature changes, all samples and standards should be taken within a close time frame to eliminate variation between sampling conditions of samples and standards. Weighed aliquants can be used but are more time consuming and offer little improvement in precision over properly dispensed volume aliquants. Standards are pipetted into flasks delivering plutonium at five or more levels from 2 to $10 \mathrm{mg}$ per flask in the optimum range (the range may be extended at the expense of precision). A calibrated automatic pipette works well for this purpose.

\section{Instrumentation - Guided Wave Model 260}

The Guided Wave Model 260 is a high resolution, high precision, UV/Vis/NIR, fiber optic instrument. The operation conditions are discussed in detail in a report evaluating an earlier model of this instrument (8). A brief list of key components and parameters using the Model 260 are given here: 
Fibers $-2 \mathrm{~m} \times 500 \mathrm{um}$ from source to cell

$2 \mathrm{~m} \times 300 \mathrm{um}$ from cell to detector

Parameters - Source - Tungsten Halogen Lamp

Filter $-495 \mathrm{~nm}$ Cut Off

Grating - 800 lines $/ \mathrm{mm}$

Detector - Si

Range - 800-860 nm

Step $-0.1 \mathrm{~nm}$

Dwell - 0 dark cycles before reading after grating movement

Rate -5 points per wavelength

Average - 3 scans per sample

Cell $-1 \mathrm{~cm}$ path, $80 \mathrm{ul}$ micro flow cell, thermostated to $\pm 0.1^{\circ} \mathrm{C}$

Peripherials - Autosampler

Peristaltic pump

\section{Reagents and Supplies}

$\mathrm{HNO}_{3}-2 \mathrm{M}$ made from reagent grade chemicals. As discussed earlier, the method is sensitive to variations in nitric acid concentration, so this reagent is made in large batches to ensure that the nitric acid concentration is constant for all samples and standards in an assay.

Cerium(Ce) solution - $1 \mathrm{M}$ ceric ammonium nitrate made in water. Centrifuge this reagent using a clinical centrifuge ( $10 \mathrm{~min}$ at full speed) to remove particulates.

Note: Distilled or deionized water must be used for all reagents.

Pipette - We use a Rainin automatic pipette. The pipette must be calibrated for all volume settings that are used in an assay. Replicate doses at a single setting can be used as follows:

If the standard stock solution is $4 \mathrm{mg} \mathrm{Pu} / \mathrm{ml}$, then five standards, A- E, over the calibration range from $2 \mathrm{mg} \mathrm{Pu} /$ flask to $10 \mathrm{mg} \mathrm{Pu}$ /flask can be prepared using a cálibrated 500 ul pipette. For standards use $A=1 \times 500, B=2 \times 500, C=3 \times 500$, $\mathrm{D}=4 \times 500$, and $\mathrm{E}=5 \times 500$ ul for the calibration standards. Then for samples use the same $500 \mathrm{ul}$ setting and replicate doses as needed. The calibration at $500 \mathrm{ul}$ is needed to measure the exact amount of plutonium in a single dose of the standard. For our purposes, precision of $0.1 \%$ or better is required.

Flasks - $50 \mathrm{ml}$, calibrated, glass volumetric flasks are used for this assay.

\section{Method}

To standards, samples (adjusted for acidity if needed), and a reagent blank in assay flasks, add $1 \mathrm{ml}$ of freshly centrifuged Ce solution to each flask. Rinse sides of flasks with $2 \mathrm{M}$ $\mathrm{HNO}_{3}$, dilute to volume, and mix well. The spectrophotometer should be on and exhibit a 
stable baseline with water before collecting data. All solutions are fed into the cell by means of a pump in conjunction with an autosampler or an equivalent technique. The volume in the cell is $80 \mathrm{ul}$ but the amount required for a prerinse and to fill the lines entering and exiting the cell is dependent on the individual system and is about five milliliters for our instrument configuration. Once the cell is filled with the solution, the flow of solution is stopped before measurement of the spectra. The spectral scan of a single solution takes about four minutes using the operational parameters listed under the Instrumentation section. The reagent blank is introduced into the cell first and the absorbance measured and stored. Standard and sample spectra are measured against the reagent blank spectra. The cell is rinsed with the next sample/standard and filled with the same solution; then a spectrum is taken and the data is stored on disk. The data stored on disk is analyzed after all the sample/standard spectra are taken. With the autosampler, the entire batch of samples and standards can be run unattended. Although ceric oxidation and aborbance measurement are usually done on the same day, the ceric complex is stable for more than two weeks. The solutions can be measured spectrophotometrically days after preparation but it is recommended that the spectra for standards and samples be collected on the same day.

\section{Data Handling}

To determine the net absorbance for the prominent $\mathrm{Pu}(\mathrm{VI})$ peak, first determine the wavelength of the maximum absorbance in each spectrum. The peak may drift slightly over the course of several hours because of instrumental instability. A baseline value is computed as the average of the two absorbances at $10 \mathrm{~nm}$ to each side of the peak. The net absorbance is the maximum absorbance minus the baseline value. This is calculated using a program which reads the spectral files and returns the net maximum absorbance for each standard and sample.

A calibration curve is generated using the net absorbances and the corresponding concentrations of the standards in $\mathrm{mg} \mathrm{Pu} / \mathrm{ml}$. The curve with the best residual form and correlation for this data is a quadratic form. A linear fit yields residuals that have a parabolic form, indicating a next order fit. Quadratic fits yield a random pattern for the residuals. The precision of the calibration curve is estimated by the average per cent residual when comparing absorbance measured versus absorbance calculated by the calibration curve parameters. Using the parameters generated, a simple calculation yields the concentration of the sample. Then using the volume of sample added to the flask, the concentration of the original sample is readily available as shown below. An example of calibration data is also shown.

Sample Concentration $=50^{*} \mathrm{X}^{*} \mathrm{CF} / \mathrm{Vol}$ of Sample Aliquot

where $\mathrm{X}=$ Concentration in the assay flask $\mathrm{CF}=$ Calibration Factor for 50ml assay flask 
and $\mathrm{X}$ is found by solving

Absorbance Measured $=a_{2} X^{2}+a_{1} X+a_{0}$

where a's are the calibration coefficients generated by a quadratic fit of the calibration data

Example Calibration Data:

\begin{tabular}{|c|c|c|c|}
\hline $\begin{array}{l}\text { Total mg } \\
\mathrm{Pu} / \text { Flask }\end{array}$ & $\begin{array}{l}\text { Pu Concentration* } \\
\mathrm{mg} / \mathrm{ml}\end{array}$ & Net Absorbance & $\%$ Residual \\
\hline 1.12450 & 0.022497 & 0.03260 & -0.132 \\
\hline 2.24900 & 0.045018 & 0.06601 & +0.050 \\
\hline 3.37349 & 0.067538 & 0.09924 & +0.082 \\
\hline 4.49799 & 0.090095 & 0.13220 & -0.032 \\
\hline 5.62249 & 0.112657 & 0.16512 & -0.038 \\
\hline 6.74699 & 0.135030 & 0.19771 & +0.006 \\
\hline 7.87149 & 0.157546 & 0.23029 & +0.008 \\
\hline
\end{tabular}

* Flask calibrations are used in determining the Pu concentration in the assay flask. Absorbance $=-0.14867 \mathrm{X}^{2}+1.4901 \mathrm{X}-0.000805$

Average absolute percent residual $=0.05 \%$

Notice that since $\mathrm{X}$ at mid-range is approximately $0.1 \mathrm{mg} / \mathrm{ml}, \mathrm{X}^{2}$ is 0.01 , and the quadratic component is only $1 \%$ of the observed absorbance. The quadratic component is not discernible upon visual examination of the calibration curve below.

\section{Calibration Curve}

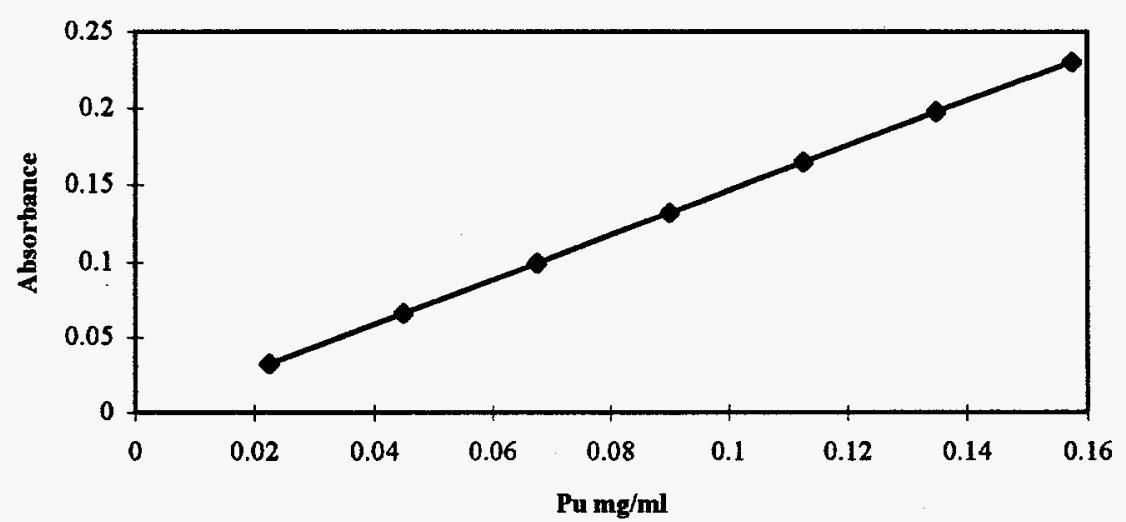




\section{Appendix}

\begin{tabular}{|c|c|c|c|c|c|c|c|}
\hline Sample & Sample & & & & & & \\
\hline Est. Conc. & Aliquant & & Sam & ple Aci & & & \\
\hline $\mathrm{mg} \mathrm{Pu} / \mathrm{ml}$ & ul & $3 \mathrm{M}$ & $4 \mathrm{M}$ & $5 \mathrm{M}$ & $6 \mathrm{M}$ & $7 \mathrm{M}$ & $8 \mathrm{M}$ \\
\hline$>50$ & 50 & 25 & 50 & 75 & 100 & 125 & 1. \\
\hline $15-50$ & 100 & 50 & 100 & 150 & 200 & 250 & 30 \\
\hline $5-15$ & 500 & 250 & 500 & 750 & 1000 & 1250 & 15 \\
\hline $1-5$ & 1000 & 500 & 1000 & 1500 & 2000 & 2500 & 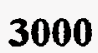 \\
\hline
\end{tabular}

Adjustments are made using the table above as a guide to indicate the ul of water to add to the assay flask as indicated in bold type. The amount of water needed is a function of both the nitric acid molarity of the sample and the aliquant size. There is no correction where the numbers are in italic since the change in acidity has a negligible effect on the method. 


\section{References}

1. T.W. Newton and F.B. Baker, "Chloride Complex Ions of Pu(VI)," J. Phys. Chem. 61, 934-938 (1957).

2. K. Buijsm, B. Chavanc DeDalmassy, and M.J. Maurice, "A Rapid and Specific Determination of Traces of Plutonium with a Recording Spectrophotometer," Anal. Chim. Acta 43, 409-415 (1968).

3. P. Cauchetier, "Determination of Plutonium by Spectrophotometry of Plutonium(VI)," Analusis 8 (8), 336-343 (1980).

4. P.G. Hagen and F.J. Miner, Spectrophotometric Determination of Plutonium III, IV, ands VI in Nitric Acid Solutions," Rocky Flats Plant report RFP-13910 (11969).

5. D.J. Savage and N.D. Cook, "Spectrophotometric Measurement of Total Plutonium after Cerium IV Oxidation," United Kingdom Atomic Energy Authority report ND-R309(D) (1980).

6. Darryl B. Smith, Genara R. Jaramillo, "Safeguards and Security Research and Development Progress Report October 1993 - September 1994." pp. 22-24, Los Alamos National Laboratory report LA-12953-PR(1995).

7. J.W. Dahlby, R.R. Geoffrion, and G.R. Waterbury, "The Sealed-Reflux Dissolution System," Los Alamos Scientific Laboratory report LA-5776(1975).

8. L.F. Walker, D.J. Temer, and Elmer Lujan, "Evaluation of the Guided Wave Model 200 Scanning Spectrophotometer for Plutonium(VI) Determination," Los Alamos National Laboratory report LA-12065-MS(1991). 